\title{
A Discussion on the Differences between Problem-based Learning and Project-based Learning
}

\author{
$\mathrm{Ke} \mathrm{SUN}{ }^{1,{ }^{*}}$ and Zhi-yong $\mathrm{LI}^{2}$ \\ ${ }^{1}$ School of Business, Jiaxing University, P.R.China \\ ${ }^{2}$ College of Civil Engineering and Architecture, Jiaxing University, P.R.China \\ asunke326@aliyun.com \\ ${ }^{*}$ Corresponding author
}

Keywords: PBL, PjBL, Differences.

\begin{abstract}
This paper qualitatively analyzes the characteristics and implementation process of two different kinds of learner focused strategies, problem-based learning (PBL) and project-based learning (PBjL). By way of comparative analysis, this paper illustrates major distinctions between these two learning methods, including start, model, tutor's and student's role, et al. This paper may help tutors do better in their teaching career.
\end{abstract}

\section{Introduction}

With the development of internationalization and globalization, the competitions between people are more intense, so it's important to cultivate the student's diversified abilities, for instance the ability to solve problems, ability to use theory in practice, team working, self-evaluation, strategic thinking and realization of complex project through innovated teaching and learning methods. Lecturing is without doubt effective for transmitting information but if we wish to achieve these goals, more student-centered approaches must be taken. It needs to involve a change in the role of the lecturer from presenting information to students to facilitating and guiding learning. So here come two different kinds of learner focused strategies, namely two PBLs, problem-based learning and project-based learning. The terms problem-based learning and project-based learning are each used to describe a range of instructional strategies. The breadth of their respective definitions, their conceptual similarity, and the use of the shorthand term PBL result in some confusion in the literature. Although project-based learning and problem-based learning share much in common, they are two distinct approaches. In problem-based learning, a specific problem is specified by the course instructor. Students work individually or in teams over a period of time to develop solutions to this problem. This instructional approach is widely used in architecture education, business education, medical education, and in other situations where 'case study' methods provide a useful focus in teaching/learning. While in project-based learning, students have a great deal of control of the project they will work on and what they will do in the project. The project may or may not address a specific problem.

This paper focuses on the differences between two PBLs. By discussing the main characteristics and implementation process of these two PBLs, this paper summarizes their distinctions and tries to give beneficial suggestions in their applications in tutors' teaching process. For convenience of expression, in this paper these two PBLs are called as PBL (for problem-based learning) and PjBL (for project-based learning), respectively. 


\section{Problem-based Learning (PBL) and Its Characteristics}

The Problem-based learning (PBL) refers to an instruction method in which the teacher builds his instruction around a practical problem and encourages pupils to discuss the problem in small groups, with an aim to cultivate active learning, critical thinking, and problem-solving skills among them. Unlike traditional instruction, PBL actively engages the student in constructing knowledge and emphasizes a "real-world" approach to learning: a student-centered process that is both constructive and collaborative. It also based on the promise that students will be motivated to "want to know" and solve the problem posed because it is presented in a context that simulates real situations. Evidences have shown that PBL is an effective tool to foster students developing the critical and creative thinking skills as well as enhance their innovation capabilities through the process of problem solving. Problem-based learning is both a curriculum and a process. The curriculum consists of carefully selected and designed problems that demand from the learner acquisition of critical knowledge, problem solving proficiency, self-directed learning strategies, and team participation skills. The process replicates the commonly used systemic approach to resolving problems or meeting challenges that are encountered in life and career.

There are six core characteristics of problem based learning (Barrows, 1996): (1) Its learning is student-centered. Although the students are guided by a tutor, they must take responsibility for their own learning, identifying what they need to know to manage the problem and where to find the information. (2) Learning occurs in small groups. At the end of each curricular unit, the students are resorted randomly to new groups. (3) Teachers act as facilitators. The role of the facilitator is not to give lectures or factual information or to direct students to sources or direct their efforts. Rather, the facilitator should ask students the kinds of questions that they should be asking themselves to understand and manage the problem. (4) A problem forms the basis for organized focus and stimulus for learning. A problem can be presented in different formats (i.e. written case, videotape, computer simulation) and it represents the challenge which the students will face in practice, providing the relevance and motivation for learning. Thus, the problem gives students a focus for integrating information, which can facilitate later recall and application to future problems. (5) Problems stimulate the development and use of problem solving skills. The best problems are engaging, contemporary and authentic. Problems mirror what students would find in real life. (6) New knowledge is obtained through means of self-directed learning. The students are expected to learn and accumulate expertise by virtue of their own study and research, just like professionals do. During this self-directed learning, students work together, discussing, comparing, reviewing, and debating what they have learned.

The details of how PBL process is implemented differ from university to university, from institution to institution and from tutors to tutors. However the general principles remain the same, especially the roles of tutors. Problem based learning encourages educators to rethink and change their educational role away from one in which they predominantly transmit facts. Fear of derailing students' self motivation must be balanced against the need for timely, thought provoking comments that guide the breadth and depth of learning without imparting facts.

\section{Project-based Learning (PjBL) and Its Characteristics}

PjBL (Project-based learning) is similar to problem-based learning in that the learning activities are organized around achieving a shared goal (project). This instructional 
approach was described by Kilpatrick (1921), as the Project Method and elaborated upon by several researchers, including Blumenfeld, et al. (1991). The project-organized concept moves the perspective from description and analyzing into synthesizing and assessment. The concept is based on a dialectic interaction between the subjects taught in the lecture courses and the problems dealt with in the project work. In project-based learning, students go through an extended process of inquiry in response to a complex question, problem, or challenge. Rigorous projects help students learn key academic content and practice necessary skills (such as collaboration, communication and critical thinking).

$\mathrm{PjBL}$ is an individual or group activity that goes on over a period of time, resulting in a product, presentation, or performance. The Buck Institute for Education (BIE) defines $\mathrm{PjBL}$ as a systematic teaching method that engages students in learning essential knowledge and life-enhancing skills through an extended, student-influenced inquiry process structured around complex, authentic questions and carefully designed products and tasks. Within a project-based approach learners are usually provided with specifications for a desired end product and the learning process is more oriented to following correct procedures. The project work is carried out by groups of four to six students having a teacher appointed as their supervisor. While working on a project, learners are likely to encounter several 'problems' that generate 'teachable moments'. Teachers are more likely to be instructors and coaches (rather than tutors) who provide expert guidance, feedback and suggestions for 'better' ways to achieve the final product.

The majority of PjBL practitioners agree on a few things that set project-based learning apart from the typical classroom experience: (1). It is inherently holistic in scope and depth. Students see a project from start to finish in both a linear and cyclical process. (2)It offers students choice in their learning. Whether the choice begins under the structure of a teacher-developed project or whether the project is entirely student-derived and the teacher provides the support for the student to carry out the project, there are impacting choices being made by the student.

There are five criteria offered to consider what kind of project can be considered an instance of PjBL (Thomas, 2000): (1) Centrality. PjBL is central to the curriculum, rather than serving to provide illustrations, examples, additional practices, or practical applications for material taught initially by other means. (2) Driving questions. These are questions or "ill-defined problems" (Stepien and Gallagher, 1993) that enable learners to make a connection between activities and the target knowledge or skills. (3) Constructive investigation. Projects must involve the transformation and construction of knowledge on the learner's part. In addition, the activities must present some difficulty to the learners so that they cannot be carried out with the application of already-learned information or skills; otherwise, the project becomes a simpler and somewhat traditional type of exercise. (4) Autonomy. Projects are learner-driven. Learner's autonomy, choice, unsupervised work time, and responsibility are incorporated into the project. Furthermore, neither questions nor outcomes are teacher-led or predetermined. (5) Realism. Projects are realistic, not school-like. Authenticity should be found in task, topic, roles, collaborators, contexts, audience, and products. 


\section{Main Differences between PBL and PjBL}

As defined in the literature, project-based learning and problem-based learning share several characteristics. Both are instructional strategies that are intended to engage students in authentic, "real world" tasks to enhance learning. Students are given open-ended projects or problems with more than one approach or answer, intended to simulate professional situations. Both learning approaches are defined as student-centered, and include the teacher in the role of facilitator or coach. Students engaged in project- or problem-based learning generally work in cooperative groups for extended periods of time, and are encouraged to seek out multiple sources of information. Often these approaches include an emphasis on authentic, performance-based assessment.

Despite these many similarities, PBL and PjBL are not identical approaches. Problem-based means that traditional textbook-knowledge is replaced by the knowledge necessary to solve theoretical problems. The problem-based concept moves the perspective from understanding of common knowledge into ability to develop new knowledge. The aim of the project work is 'learning by doing' or 'action learning'. The project work may be organized by using a 'know-how' approach for training professional functions, or it may be organized by using a 'know-why' approach for training methodological skills of problem-analysis and application. The former is normally applied in first half of the curriculum where the necessary disciplines are taught in the lecture courses. The latter is applied in the second half of the curriculum and is supported by lecture courses presenting the necessary theories within the specific professional areas. It is for this point that it's necessary to make a difference between PBL and PjBL. According to Savin-Baden (2003) and other literatures, the major differences between PBL and PjBL can be summarized as table 1.

Table 1 Differences between PBL and PjBL

\begin{tabular}{ccc}
\hline & PBL & PjBL \\
\hline Start & with a problem & with an end product \\
Model & inquiry model & production model \\
Tutors' role & facilitate & supervise \\
Students' role & initiative & passive \\
Focus & problem-management & produce a solution \\
Necessity of lectures & not usually used & supporting lectures needed \\
\hline
\end{tabular}

\section{Start}

Problem-based learning, as the name implies, begins with a problem for students to solve or learn more about. Often these problems are framed in a scenario or case study format. Problems are designed to be 'ill-structured' and to imitate the complexity of real life cases. As with project-based learning, problem-based learning assignments vary widely in scope and sophistication. Project-based learning typically begins or 'artifact' in mind, the production of which requires specific content knowledge or skills and typically raises one or more problems which students must solve. Projects vary widely in scope and time frame, and end products vary widely in level of technology used and sophistication.

\section{Model}

PBL follows an inquiry model. Students are presented with a problem and begin by organizing any previous knowledge on the subject, posing any additional questions, and 
identifying areas they need more information. They can devise a plan for gathering more information, and do the necessary research and reconvene to share and summarize their new knowledge, then present their conclusions, and there may or may not be an end product. Again, students ideally have adequate time for reflection and self-evaluation (Delisle, et al., 1997; Stepian and Gallagher, 1993). All problem-based learning approaches rely on a problem as their driving forces, but may focus on the solution to varying degrees. Some problem-based approaches intend for students to clearly define the problem, develop hypotheses, gather information, and arrive at clearly stated solutions (Allen, 1998). Others design the problems as learning-embedded cases which may have no solution but are meant to engage students in learning and information gathering (Wang, 1998).

In contrast, $\mathrm{PjBL}$ follows a production model. Students define the purpose for creating the end product and identify their audience. They research their topic, design their product, and create a plan for project management. Then they begin the project, resolve problems and issues that arise in production, and finish their product. Students may use or resent the product they have created, and ideally are given time to reflect on and evaluate their work (Crawford, et al.). The entire process is meant to be authentic, mirroring real world production activities and utilizing students' own ideas and approaches to accomplish the tasks at hand. Though the end product is the driving force in project-based learning, it is the content knowledge and skills acquired during the production process that are important to the success of the approach.

\section{Other Differences}

For the roles of tutors and students, problems usually provided by staff but what and how they learn defined by students, so tutor facilitates the students in PBL. While in $\mathrm{PjBL}$, tasks are predominantly orientated with activity often set by tutor, so tutor supervises the students. Not only that, for PBL, solving the problem may be part of the process but the focus is on problem-management, not on a clear and bounded solution. While for $\mathrm{PjBL}$, students are required to produce a solution or strategy to solve the problem. Furthermore, for PBL, lectures not usually used on the basis that students are expected to define the required knowledge needed to solve the problem. While for PjBL, there may include supporting lectures which equip students to undertake activity, otherwise students expected to draw upon knowledge from previous lectures.

\section{Conclusions}

Overall, we can see some clear distinctions between PBL and PBjL. In fact, these two approaches sometime complementary. In practice, the line between project- and problem-based learning is frequently blurred and that the two are used in combination. Fundamentally, problem-based and project-based learning have the same orientation: both are authentic, constructivist approaches to learning.

\section{Acknowledgment}

This research is financially supported by the Educational Science Foundation of Zhejiang Province in China (Grant No. 2017SCG051) 


\section{References}

[1] H. S. Barrows, Problem-based learning in medicine and beyond: a brief overview, New directions for teaching and learning. 68(1996) 13-21.

[2] R. Donnelly, M. Fitzmaurice, Collaborative project-based learning and problem-base learning in higher education: a consideration of tutor and student roles in learner-focused strategies, In: Emerging Issues in the Practice of University Learning and Teaching, 2005.

[3] J. R. Savery, Overview of Problem-based Learning: definitions and distinctions, The Interdisciplinary Journal of Problem-based Learning. 1(1) (2006) 9-20.

[4] W. H. Kilpatrick, Dangers and difficulties of the project method and how to overcome them: Introductory statement: Definition of terms. http://www.tcrecord.org, 1921.

[5] Blumenfeld, P.C., et al. Motivating project-based learning: Sustaining the doing, supporting the learning, Educational Psychologist. 26(1991) 369-398.

[6] J. W. Thomas, A review of research on project-based learning, from http://www.bie.org/files/researchreviewPBL_1.pdf., 2000.

[7] W. J. Stepien, S. A. Gallagher, Problem-based Learning: As authentic as it gets, Educational Leadership. 50(7) (1993) 25-8.

[8] M. Savin-Baden. Facilitating problem-based learning: the other side of silence, SRHE/Open University Press, Buckingham, 2003.

[9] R. Delisle, How to use Problem-Based Learning in the classroom, Association for Supervision and Curriculum Development, Alexandria, VA, 1997.

[10]D. Allen, Bringing Problem-Based Learning to the introductory biology classroom. Available: http://www.saunderscollege.com/lifesci/studact/chapters/ch15.html, 1998.

[11]H. Wang, On AERA listserve on-line discussion, Research Associate, CCMB-USC, 1998. 